\section{S. aureus}

Strain 15981

\begin{tabular}{llll}
\hline \multicolumn{2}{l}{ Time (h) Gold } & Polyst. & S. Steel \\
\hline 1 & 0.290 & 0.350 & 0.291 \\
3 & 0.809 & 0.635 & 0.729 \\
\hline 5 & 3.557 & 3.566 & 3.320 \\
\hline 8 & 8.777 & 8.62 & 8.442 \\
\hline 16 & 9.988 & 10.327 & 9.686 \\
\hline 24 & 10.750 & 10.370 & 10.633 \\
\hline
\end{tabular}

\section{Strain ISP479r}

\begin{tabular}{llll}
\hline \multicolumn{2}{l}{ Time (h) Gold } & Polyst. & S. Steel \\
\hline 1 & 0.217 & 0.138 & 0.302 \\
3 & 0.345 & 0.382 & 0.397 \\
5 & 0.552 & 0.557 & 0.573 \\
\hline 8 & 0.982 & 0.927 & 0.953 \\
\hline 16 & 0.975 & 1.078 & 1.109 \\
\hline 24 & 1.873 & 1.823 & \\
\hline
\end{tabular}

\section{Strain 132}

\begin{tabular}{llll}
\hline \multicolumn{2}{l}{ Time (h) Gold } & Polyst. & S. Steel \\
\hline 1 & 0.106 & 0.101 & 0.163 \\
3 & 0.247 & 0.287 & 0.273 \\
\hline 5 & 0.540 & 0.503 & 0.558 \\
\hline 8 & 0.798 & 0.786 & 0.788 \\
\hline 16 & 0.958 & 0.977 & 1.039 \\
\hline 24 & 0.806 & 0.925 & 0.888 \\
\hline
\end{tabular}

\section{Strain V329}

\begin{tabular}{l|l|l|l}
\hline \multicolumn{2}{l}{ Time (h) Gold } & Polyst. & S. Steel \\
\hline 1 & 0.240 & 0.227 & 0.274 \\
\hline 3 & 0.920 & 0.885 & 0.918 \\
\hline 5 & 2.610 & 2.300 & 2.486 \\
\hline 8 & 9.090 & 9.257 & 9.720 \\
\hline 16 & 10.790 & 10.290 & 10.367 \\
\hline 24 & 11.040 & 10.950 & 10.820 \\
\hline
\end{tabular}
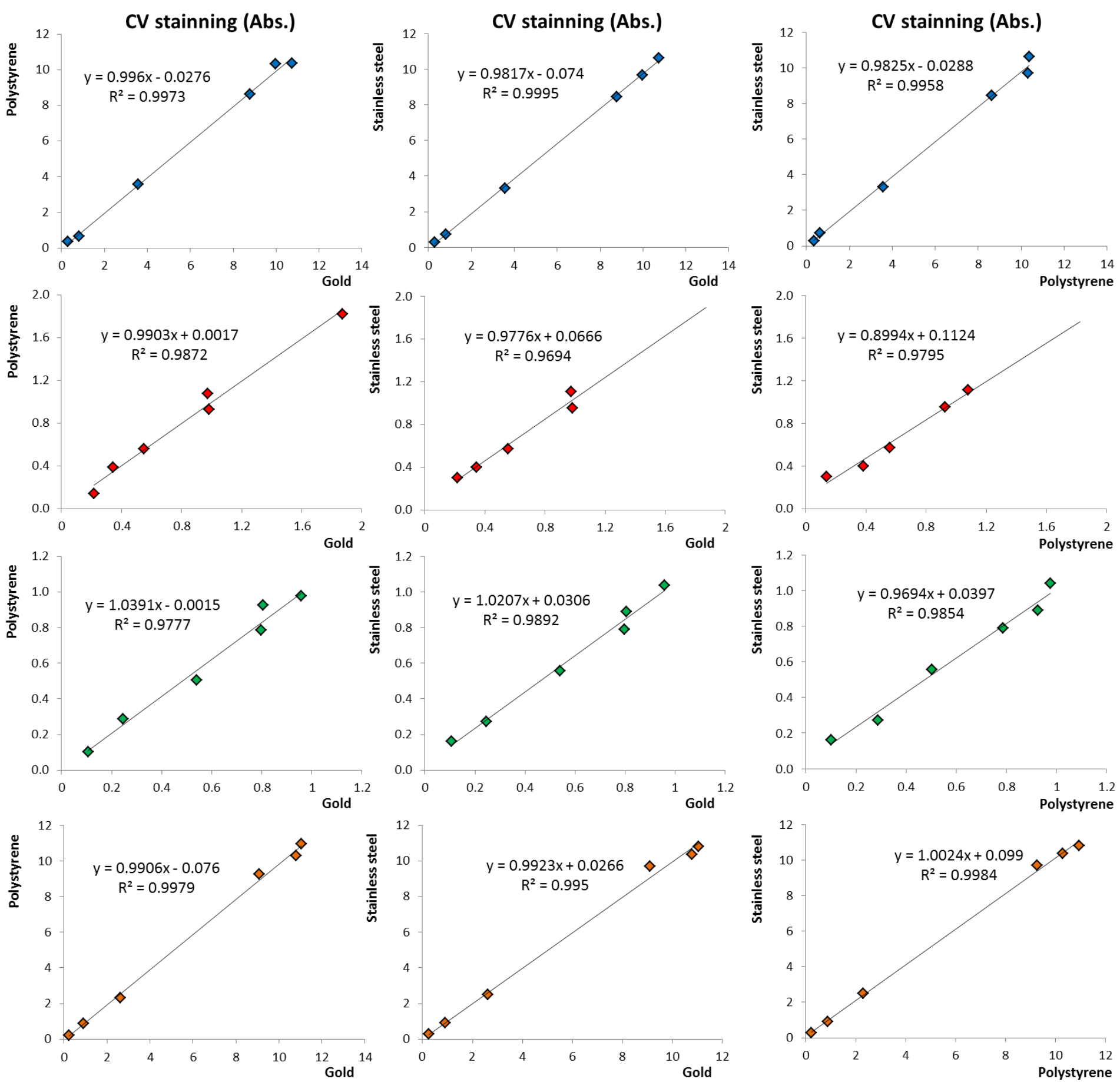


\section{S. epidermidis}
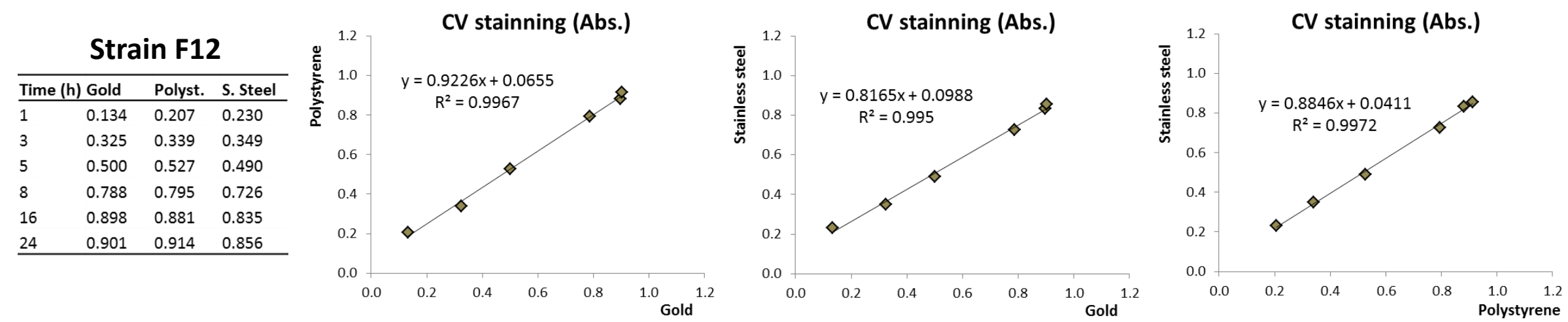